\title{
ARQUITETURA ARRUINADA
}

\author{
DESFAZER 0 ESPAÇO \\ Exposição de Gordon Matta-Clark. Museu de Arte Moderna de São Paulo (MAM-SP), fev.-abr. 2010.
}

GUILHERME WISNIK

Filho do artista surrealista chileno Roberto Matta, Gordon Matta-Clark nasceu em Nova York, em 1943. Cursou arquitetura na Cornell University, em Ithaca, onde em 1969 se aproximou de Dennis Oppenheim e Robert Smithson, no workshop Earth Art. A partir daí, desenvolveu uma carreira artística meteórica, até morrer precocemente de câncer em 1978, aos 35 anos de idade, na cidade onde nasceu. Durante apenas nove anos, portanto, Matta-Clark criou uma obra prolífica e intensa, que combinou intervenções escultóricas em espaço urbano com forte caráter transgressivo, happenings, vídeos, ações comunitárias e crítica institucional, atuando no sentido de explodir a tradicional fronteira entre arte e vida.

Suas intervenções foram fugazes e feitas na forma de trabalhos site-specific, isto é, aderidos às condições únicas do lugar no qual se implantaram, e por isso passíveis de serem contemplados apenas por aqueles que estiveram presentes no curto espaço de tempo em que eles existiram. As fotografias e os vídeos, no entanto, garantem um certo registro dessas ações e se tornam também obras de arte, só que em outro suporte. Tal é o que se viu, basicamente, na exposição "Gordon Matta-Clark: desfazer o espaço", que esteve no Museu de Arte Moderna de São Paulo (MAM) entre fevereiro e abril últimos. Com curadoria de Tatiana Cuevas, do Museo de Arte de Lima (Peru), e de Gabriela Rangel, diretora de artes visuais da Americas Society em Nova York, a retrospectiva itinerante que vem percorrendo a América Latina apresentou um conjunto bastante abrangente da obra do artista - descontando-se a evidente dificuldade de se representar em desenhos, fotos e vídeos a complexidade de trabalhos profundamente dependentes de uma apreensão física real. 
Apesar de ter abandonado a arquitetura logo após ter se formado,em 1968, Matta-Clark elegeu-a como o tema central de sua arte. Antes de tudo, a negatividade contundente de suas intervenções em edifícios existentes tem influência do niilismo escatológico de Georges Bataille, escritor surrealista dissidente, para quem a arquitetura representa a encarnação da geometria autoritária que ampara o funcionamento da sociedade. É justamente em contraposição a essa razão ordenadora "arquitetônica" - a um tempo artificial e ilusória — que Bataille afirma o caráter informe do mundo, excluindo qualquer hipótese de inspiração mimética para as artes. $\mathrm{O}$ "universo não se assemelha a nada", diz ele, "é

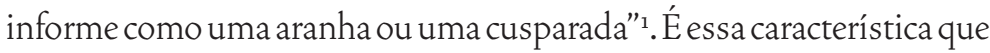
leva Rosalind Krauss eYve-Alain Bois a dizerqueas ações de Matta-Clark não se esgotam no afrontamento físico dos edifícios em si, mas visam, antes de tudo, colocar em xeque a própria função social da arquitetura ${ }^{2}$.

Já na obra de Robert Smithson, no final dos anos de 1960, a arquitetura aparece como um sistema de ordenação que entra em falência diante da entropia da natureza, como sevêem Partiallyburied woodshed (1969), ondeumacasasubmergeemmeioaummontedeterra.OqueMatta-Clark faz, em seguida, assim como também Richard Serra,é trazer alguns princípios da land art, como o site-specific, para o interior da cena urbana. Portanto, mais do que um tema, na verdade, a arquitetura é a entidade físicaesimbólicamaisatacadanasviolentasintervenções deMatta-Clark, na forma de cortes em edifícios existentes. Munido de picaretas e serras-elétricas manuais, ele invadia (sozinho, ou com poucos assistentes) construções abandonadas, perfurando e extraindo partes de vigas, lajes, paredes, portas, janelas ou telhados. Como numa colagem cubista às avessas e em grande escala, ele não apenas tomava artefatos arquitetônicos como grandes ready-mades, deslocando-os de seu contexto original, mas também os ressignificava, mutilando-os por dentro. Como observou o artista Dan Graham, sua obra é uma espécie de "agit prop urbana"3, semelhante à ação dos situacionistas em Paris. Quer dizer, o ataque de Matta-Clark à arquitetura diz respeito à ilusão de perenidadee eficiência que nela se materializa, e que faz dela uma poderosa metáfora do status quo social. Assim, ao procurar eliminar sua "coluna vertical semântica"4, o artista revela o caráter efêmero, precário e ideológico da arquitetura como construção simbólica, atacando também o ciclo de produção e consumo da cidade: sua obsolescência programada, o descaso com os bairros suburbanos e compartimentaçãoalienantedos espaços domésticos, normalmente ocultada pela uniformidade protetora das fachadas.

\begin{abstract}
[1] Bois, Yve-Alain e Krauss, Rosalind. Formless: a user's guide. Nova York: Zone Books, 1997, p. 5. Extraído de Bataille, Georges. Visions of excess, traduzido a partir de Oeuvres complètes. Paris: Gallimard, 1970-1988.
\end{abstract}

[2] Cf. Bois e Krauss, op. cit., p. 188.

[3] Graham, Dan."Gordon MattaClark”. In: Diserens, Corinne (org.). Gordon Matta-Clark. Londres: Phaidon, 2003, p. 199.

[4] Brouwer, Marianne. "Dejando al descubierto". In: Casanova, Maria (org.). Gordon Matta-Clark. Valéncia: Ivam, 1993, p. 51.

\section{ARTE DE RUA, ATIVISMO COMUNITÁRIO}

Aobra de Matta-Clark está muito vinculada ao universo da contracultura è vitalidade da vida de rua em bairros como o SoHo, em Nova 
[5] "Anarchitecture" é o nome auto-atribuído a um grupo de artistas reunidos em 1973, cujos encontros resultaram em uma exposição homônima e anônima no ano seguinte. Inventado por Matta-Clark, o termo funde as palavras "anarquia" $e$ "arquitetura", podendo ser tomado como um conceito-síntese do seu trabalho.
York, que nos anos de 1960 e 1970 eram desvalorizados e ocupados por imigrantes, trabalhadores manuais e artistas. Vivendo predominantemente de forma comunitária, Matta-Clark tocou, entre 1971 e 1972, um restaurante chamado Food na rua Prince, que era um lugar de happenings e improvisações artísticas e culinárias. É também dessa época a sua ação/vivência chamada Tree dance, transformada em um pequeno filme, em que grupos de pessoas se movimentam dentro de redes translúcidas presas no alto de árvores, em Nova York.

Logo no início da carreira, o artista se interessa pela realidade pouco glamorosa de bairros periféricos da cidade, realizando ações e filmes em áreas debaixo de pontes, em ferros-velhos e túneis subterrâneos, como Jacks under the Brooklyn Bridge e Fire boy (1971). Vem dessa experiência marginal obras posteriores eengajadas em um forte ativismo comunitário, como Open house, uma pequena e precária casa-contêiner ambulante sobre rodas, e Fresh aircart (1972), um carrinho capaz de transportar duas pessoas num passeio pela cidade vestindo máscaras conectadas em um tubo de oxigênio. Esse percurso culmina na formaçãodogrupomultimídiachamado "Anarchitecture" (1973-1974), composto por doze jovens artistas incluindo performers e músicos, como Laurie Anderson, com o objetivo de criar trabalhos colaborativos. O nome do grupo indica uma aproximação subversiva entre as palavras arquitetura e anarquias.

\section{EDIFÍCIOS CORTADOS}

O artista começa a experimentar cortes e extrações de partes de edifícios existentes a partir de 1973. Porém, é no ano seguinte que faz sua primeira intervenção significativa, chamada Splitting (1974). Apropriando-se de uma casa abandonada em Nova Jersey, ele a secciona rigorosamente ao meio, abrindo um rasgo de luz no seu interior, e suspende uma das metades pela base de modo a fazê-la inclinar-se levemente. No ano seguinte, o minimalismo formal do corte ao meio dá lugar a intervenções mais barrocas em formatos circulares, como em Day's ende Conical intersect. No primeiro, ele corta fragmentos de um píer abandonado em Manhattan, numa ação transgressiva que, por desrespeitar as leis de segurança pública e de inviolabilidade da propriedade privada, lhe rendeu uma ordem de prisão. No segundo, faz buracos cônicos em edifícios que seriam demolidos para a construção do Centro Georges Pompidou, no bairro do Marais, em Paris, denunciando a violência daquela operação urbana.

Em Office-baroque (1977) e Circus - Caribbean orange (1978), o artista como que inscreve figuras geométricas vazias no interior de edifícios, fazendo seccionamentos semi-circulares e espirais. Mas se, de um lado, o resultado dessas obras leva a um embaralhamento 
na apreensão da profundidade espacial, de outro, a operação artística visa a uma restauração da experiência cognitiva: a liberação de vazios interiores que dinamizem a percepção daquilo que se encontrava enrijecido, fragmentado. Nesse sentido, atua na direção contrária à do laconismo minimalista - que se restringe a agenciar a exterioridade visível dos objetos - , fazendo do próprio corpo do artista, e dos visitantes das obras, um instrumento determinante no balé coreográfico que estabelece com o espaço. A idéia de Circus, diz ele, remete-se à arena de um circo. É "um lugar para a atividade, um círculo para a ação" 6 .

\section{CRÍtica URBANA E INSTITUCIONAL}

Não apenas a arquitetura, mas também o espaço urbano é objeto de denúncia do artista. Em 1973, realizou a obra Reality properties: fake estates (1973), em que comprava parcelas mortas de terrenos em Nova York - como um quadrado de 30 centímetros em um miolo de quadra, ou uma faixa linear de apenas 1 metro de largura entre duas ruas - por apenas 25 dólares. Uma vez proprietário desses terrenos insólitos, ele fixava uma plaquinha com seu nome e as fotografava, além de mapear os lotes em um planta da cidade, expondo todo esse material em galerias e museus. A inteligência da obra comenta não apenas a irracionalidade dos processos urbanos oculta sob a aparente disciplina ordenadora das suas edificações, mas também acusa o processo de apagamento de setores menores e mais comunitários da cidade pela impessoalidade desagregadora do processo de modernização capitalista, tal como denunciado por Jane Jacobs desde o início dos anos de 1960 . Pode-se dizer, por essa via, que as mutilações que realiza em edifícios abandonados replicam, inversamente, as cicatrizes urbanas abertas por Robert Moses na malha viária desses mesmos bairros, substituindo antigas ordens comunitárias pela impessoalidade fáustica e desagregadora da modernização capitalista.

Em 1976, Matta-Clark foi convidado a participar de uma exposição coletiva no edifício do Institute for Architecture and Urban Studies (Iaus), dirigido por Peter Eisenman, considerado o templo da arquitetura nova-iorquina de então. Expondo fotos de prédios com vidros estilhaçados em áreas violentas do Bronx, o artista quebrou inadvertidamente todas as janelas do Instituto durante a noite que antecedia a inauguração do evento, numa ação extremamente polêmica, que chamou de Window blow-out7. Trata-se de uma das obras pioneiras de crítica institucional, em que o artista coloca em xeque o conteúdo simbólico da própria organização que o suporta. Através dessa metáfora é como se a arte, ao ter definitivamente inva-
[6] Gordon Matta-Clark, citado por Kirshner, Judith Russi, "Nonuments". In: Casanova, op. cit., p. 59 .
[7] O evento fez parte da exposição "Idea as model", realizado no edifício do Iaus. Segundo Andrew MacNair, Eisenman reagiu violentamente ao "ataque", comparando-o à "noite dos vidros quebrados" na Alemanha, em referência à ofensiva nazista aos estabelecimentos judaicos. Cf. Casanova, op. cit., pp. 52-3. 
[8] Ver Krauss, Rosalind. "Sculpture in the Expanded Field". In: The originality of the avant-garde and other modernist myths. Cambridge (Mass.): The MIT Press, 1985. dido o espaço do mundo comum, antes "território" da arquitetura, quisesse incutir nela a sua crise, tentando arrastá-la para uma "morte" a dois. Morte que, no entanto, nada mais é do que um renascimento. Nem arte, nem arquitetura stricto sensu, a partir de então. Mas sim, aquilo que Rosalind Krauss chamou de "campo ampliado" ${ }^{8}$ : ações críticas no espaço que já não se encerram em campos disciplinares puros e autônomos. Atividades contaminadas pela heterogeneidade imperfeita do mundo real, da qual elas são ao mesmo tempo parte e contraponto.

GUILHERME WiSNiKé arquiteto e mestre em história social pela Universidade de São Paulo. É autor de Lucio Costa (Cosac Naify, 2001) e Estado crítico:à deriva nas cidades (Publifolha, 2009). 